\title{
Uma Heurística do Sentido para a Tecnologia: a Busca do Bem Estar
}

\section{A Heuristics Sense for the Technology: the Quest for Wellness}

Afonso Vieira ${ }^{1}$

\begin{abstract}
Resumo
A discussão que permeia este artigo está associada à proposta de um tipo de agir científico que tange à produção de tecnologia baseada na ética da responsabilidade. Tem como objetivo, através de um estudo exploratório, a busca de uma heurística de sentido para a tecnologia, ou seja, refletir sobre a técnica na vida do ser humano como um impulso de sua curiosidade tendo em vista a satisfação de suas necessidades objetivas e àquelas que transcendem. Procura-se por fim, compreender que a "era tecnológica" é fruto de uma Weltanschauung", compreendida por Immanuel Kant (1724-1804), na Crítica do Juízo, como a capacidade humana de perceber a realidade sensível, isto é, como concepção de mundo em que o domínio da natureza através da tecnologia se agiganta de modo a criar obstáculos para o aprofundamento ontológico do saber e para que o agir humano possa voltar a maravilhar-se por tudo aquilo que faz, desde que todas as atividades por ele engendradas visem, como ponto causal, ele próprio.
\end{abstract}

Palavras-chave: Tecnologia. Ética da responsabilidade. Curiosidade. Necessidade. Sentido.

\section{Abstract}

The discussion that permeates this article is associated with the proposal for a scientific kind of act with respect to production technology based on the ethics of responsibility. It aims, through an exploratory study, the search for a heuristic sense for the technology, that is, reflect on the technique in human life as an impulse of curiosity in order to satisfy their objective needs and those that transcend. We try to finally understand that the "technological age" is the result of a Weltanschauung, understood by Immanuel Kant (1724-1804), in the Critique of Judgment, as the human capacity to perceive the sensible reality, i.e., a world view in which the domination of nature through technology looms to create obstacles to the deepening ontological knowledge and that human conduct can come back to marvel at for all

\footnotetext{
${ }^{1}$ Psicólogo, especialista em Administração e Mestrando no Programa de Mestrado Interdisciplinar em Organizações e Desenvolvimento FAE. E-mail para contato: studiocompasso@gmail.com.

2 Weltanschauung é a orientação cognitiva fundamental de um indivíduo ou de toda uma sociedade. Essa orientação abrange tanto sua filosofia natural quanto os seus valores fundamentais, existenciais e normativos. E também seus postulados ou temas, emoções, e sua ética. Outro sentido do termo é o de uma imagem do mundo imposta ao povo de uma nação ou comunidade, isto é, uma ideologia. É uma visão de mundo. (Conf. Wikipédia online).
}

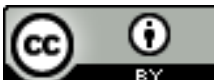

Esta obra foi licenciada com uma Licença Creative Commons - Atribuição 3.0 Não Adaptada Cad. de Pesq. Interdisc. em Ci-s. Hum-s., Florianópolis, v.13, n.102, p.202-223 jan/jun 2012 
that is provided that all activities engendered by it as aimed at causal point himself. Key words: Tecnology. Ethics of responsibility. Curiosity. Need. Sense.

Que obra de arte é um homem, quão nobre em razão, quão infinito em faculdades, quão expressivo e admirável na ação, quão como um anjo em apreensão, quão como um deus: a beleza do mundo, paradigmas entre os animais (Shakespeare, Hamlet, 1604).

\section{Introdução}

Estão abertas as cortinas para o espetáculo do terceiro milênio onde o ator principal se chama tecnologia. As possibilidades de inovações e conhecimento no campo da ciência e tecnologia, os instrumentos conceituais e metodológicos que são utilizados para conhecer a natureza humana e ambiental estão em permanente mudança e evoluem em velocidade impressionante. Com isso, desafia as competências humanas nos aspectos de gestão, de escolha e tomada de decisão para geração de tecnologias que visem à mudança social e a qualidade de vida das pessoas, isto é, produção de uma riqueza tecnológica geradora de felicidade, de bem estar.

Gerar tecnologia mais sensível aos direitos humanos, que possam satisfazer não somente as necessidades - estimuladas pelo déficit - de sobrevivência, de segurança e outras carências humanas básicas, mas também as mais elevadas como a de autorrealização, conforme elencadas por Maslow (apud FADIMAN, 1986) em sua hierarquia das necessidades. Sabemos da importância da inovação tecnológica, da "reforma que o homem impõe à natureza em vista da satisfação de suas necessidades" (ORTEGA Y GASSET, 1991, p, 12). Daí a importância do estudo das necessidades humanas fundamentais e daquelas "fundantes", onde "a vida humana não é só a luta com a matéria, mas também luta do homem com sua alma" (ORTEGA Y GASSET, 1991, p, 78). E por isso Ortega y Gasset encerra o seu livro Meditação sobre a técnica com um questionamento sobre a possibilidade de vislumbrar no mundo ocidental um claro repertório de técnicas da alma. Eu acrescentaria de técnicas de sentido, onde haveria uma mudança de paradigma em que a relação inter-humana e com a natureza seja mediada pelo absoluto e não pela tecnologia. Absoluto aqui compreendido por uma reflexão ética que busque o princípio fundamental que dê sentido ao homem e suas relações com todos os que o 
cercam. Um absoluto que leve a conscientização de uma responsabilidade que busque atender o universal, da natureza humana à extra-humana, até pelo fato de que a tecnologia atual tem seu campo de ação alargado atingindo desde o genoma humano até o plano cósmico.

Também uma tecnologia voltada para os problemas reais da sociedade, pois sabemos que ela é indispensável como estratégia para o seu desenvolvimento. Lembra-nos Furtado (1984) que a tecnologia é uma das vias mais intensas de mudança cultural dos povos e que o progresso técnico atua na transformação cultural deles, operando contínuas mudanças na base material. Nasce daqui também a reflexão sobre a destinação dos financiamentos das instituições do estado e iniciativas privadas para geração desse progresso técnico e o controle ético sobre a produção dessa tecnologia.

E isso é possível, pois

os indivíduos e as sociedades humanas, por terem consciência e por serem produtores de sentido, têm a capacidade de se afirmarem como sujeitos da sua história, de criar, em relação ao mundo, a distância que lhes permite encará-la "de fora", apesar de ser parte constitutiva desse mesmo mundo (RAYNAUT 2011, p.82).

Tendo em vista que a inovação é fruto da curiosidade e da criatividade humana, e como diz Steve Jobs, que as maiores inovações estão sempre ligadas às pessoas e não ao capital investido e às tecnologias à disposição, questionamo-nos sobre uma heurística de sentido para a tecnologia a fim de tornar a vida humana mais sustentável e feliz e plena de bem estar.

Neste artigo me proponho, portanto, através de um estudo exploratório de alguns autores, principalmente da psicologia, filosofia e sociologia, compreender o comportamento do indivíduo em seu ambiente, analisando algumas categorias como: curiosidade, necessidades e sentido, bem como discutir questões pertinentes à liberdade, autonomia e técnica, e, por fim, sugerir um princípio ético baseado na responsabilidade, que seja capaz, conforme a recomendação de Morin (apud Arruda, 2006, p.1) de cultivar 
de vida, ao passo que a segunda está baseada na compartimentação e no aumento exponencial dos saberes e das informações.

E por fim inferir que a tecnologia em si não tem problemas e, se os tem, eles existem a partir da utilização ética em que os recursos financeiros, humanos e produtivos são a ela direcionada, do modo como é pensada, escolhidas, projetada, produzida e por fim, apropriada e utilizada pelos seus usuários: quer para o desenvolvimento da sociedade e o seu bem estar ou para o seu colapso.

\section{Necessidade}

Como aprendemos a conhecer o nosso desejo? Quando tenho que temer por uma situação que me falta (JONAS, 2006).

Kurt Lewin, em sua teoria de campo, explica essa questão afirmando que todos os fatos ou acontecimentos que acontecem conosco têm uma valência, um valor, e podem ser chamados de necessidades e que irão afetar nossa região intrapessoal. Uma situação de falta gera na região intrapessoal uma tensão ou liberação de energia que resulta no aparecimento de uma necessidade. Necessidade aqui pode ser uma situação psicológica, o desejo de alguma coisa ou a intenção de fazer algo (LEWIN, 1973).

A necessidade é um conceito motivacional equivalente aos termos como motivo, desejo, impulso. Lewin não elenca um número de necessidades específicas, ou por categorias, como faz Maslow (apud FADIMAN, 1986) em sua hierarquia das necessidades. Ele diz:

o problema da emergência de necessidades situa-se na confluência da antropologia cultural, da psicologia do desenvolvimento e da psicologia da motivação. Sua investigação tem sido prejudicada por tentativas especulativas e prematuras no sentido de sistematizar as necessidades em poucas categorias (LEWIN, 1965, p. 280).

Cada necessidade é um fato concreto e se ela não for descrita em todas as suas particularidades, isto é, se não for delimitada, não nos é possível compreender por inteiro a realidade da pessoa desejante, e a busca pela satisfação da necessidade pode ficar incompleta. 
Lewin (1973) ainda diz que podem ser destacados três estados nas necessidades: um de fome, outro de satisfação e um terceiro de supersatisfação. Cada estado corresponde a um valor positivo, neutro e negativo, seguindo a ordem em relação à determinada necessidade. Por exemplo, a supersatisfação significa que o objeto ou atividade anteriormente desejada se tornou desagradável, em virtude de uma experiência contínua, pois o excesso de qualquer coisa pode produzir mal-estar e náusea.

Também ele faz uma distinção entre necessidades e um estágio de quase necessidades, explicando, por exemplo, que uma necessidade deve-se a um estado interior, como a fome, e uma quase necessidade que seria equivalente a uma intenção específica de se alimentar em determinado lugar. Lewin (1973) acredita que as necessidades das pessoas são, em grande parte, determinadas por fatores sociais.

Já Ortega y Gasset (1991) em seu livro Meditação sobre a técnica, comenta que o homem, por querer viver, sente necessidade, logo este viver se torna a necessidade originária pela qual as outras necessidades são decorrentes. $E$ tudo que lhe é negativo, que the pode atentar contra sua vida, desencadeia uma necessidade e lhe mobiliza para a busca do atendimento de satisfação dessa necessidade. Podemos dizer que se nos falta algo é que está em outro lugar, e, através da 'técnica', buscamos ou criamos um instrumento ou aparelho que nos proporcione aquilo que tínhamos necessidade. Com isso Ortega y Gasset (1991) conclui que com o conjunto de atos técnicos, a qual vai chamar de técnica, o homem modifica ou reforma as circunstâncias ou a natureza em que vive, criando entre elas e o homem uma nova natureza, uma sobrenatureza. A técnica se torna então não só um meio para a satisfação da necessidade, mas é também a reforma da natureza. Modificamos as circunstâncias e a natureza para a satisfação de nossas necessidades. Para Ortega y Gasset (1991) o conceito de necessidade humana abrange desde o homem primitivo tudo aquilo que é objetivamente necessário, quanto o que é supérfluo, pois criamos também além daquilo que é necessário situações não necessárias no sentido restrito. Voltando à alegoria bíblica de Adão e Eva no paraíso, verificamos que o reino das necessidades objetivas satisfeitas não nos satisfaz o suficiente, porque não esgota toda a nossa graça. A droga seria um exemplo de substância que coloca o homem em estado psicofisiológico de exaltação

Cad. de Pesq. Interdisc. em Ci-s. Hum-s., Florianópolis, v.13, n.102, p.202-223 jan/jun 2012 
ou estupor delicioso. Perls (2002) chamaria isso de necessidades adicionais criada pela civilização - algumas imaginárias e outras reais, de importância secundária formadoras de hábito, que produz uma necessidade real no organismo humano. Como necessidades imaginárias podem assinalar os passatempos, jogos e outras atividades ou coisas não vitais para o organismo, porém que consomem bastante interesse. Daqui, segundo Perls (2002, p. 72), é um passo para "as obsessões e fobias patológicas".

Vale lembrar ainda outro elemento que Freud (1996) acrescenta na trajetória entre a necessidade e objeto de satisfação: a representação psíquica de satisfação. O que movimenta o ser humano não é o binômio necessidade-satisfação, mas a pulsão em direção à realização de um desejo. Uma criança tem na figura materna o seu representante que mediará sua satisfação de necessidades. Dessa vinculação com seu representante, experiências prazerosas ou não ficam registradas como se fossem sinais que irão formando imagens. Portanto, para Freud o que impulsiona o homem não é em si só a necessidade enquanto tal, mas a reativação de imagens, o desejo de reproduzir experiências que lhe gerem prazer e evitar as que carregam sinais negativos (TELLEGEN, 1984).

Por fim, ainda com Ortega y Gasset, verifica-se que "o empenho do homem em viver no mundo, é inseparável de seu empenho em estar bem". O bem-estar e não o estar é a necessidade fundamental do homem. Ele constata que "as necessidades humanas existem apenas em função do bem estar. Só poderemos, então, averiguar quais são essas necessidades, se investigarmos o que o homem entende por seu bem-estar" (ORTEGA Y GASSET, 1991 p, 15-17).

Se viver, perdurar é para Ortega y Gasset a necessidade das necessidades, porque durante nossa trajetória de vida criamos tecnologias ou escolhemos as que vão em direção contrária ao nosso bem-estar? Qual o desejo primordial que aí se encontra?

Tellegen nos indica que

o desejo se origina e se calca em necessidades, mas enquanto desejo está desvinculado delas. $E$ enquanto desejo também não tem objeto único ou determinado de satisfação. Por outro lado nenhum objeto real preenche totalmente o desejo. E o espaço desta falta, no nível do desejo, é fundamental para a constituição do eu psíquico, do ser humano como transformador da natureza dada (TELLEGEN, 1984, p. 60). 


\section{Curiosidade}

Segundo Stokes (2005), em seu livro O Quadrante de Pasteur, ...uma razão tão velha quanto a Antiguidade Clássica é a crença de que um
povo civilizado procura o conhecimento pelo próprio conhecimento. A
crença na pesquisa pura como um sinal de civilização exerce sua influência
também na atualidade, e a base de apoio a essa crença é aumentada pela
curiosidade popular em torno do desconhecido (STOKES, 2005, p. 157).

A ambivalência - do ímpeto ousado de curiosidade em direção ao mundo e à tendência igualmente agressiva de bloqueá-lo - é um tipo de conhecimento tão antigo quanto a história humana. O querer saber demais já teve início com a adolescência de Adão e Eva no paraíso. Podemos até especular nesse episódio o que foi reprimido no desenvolvimento humano, isto é, a curiosidade reprimida.

Para Freud (1996), o impulso adulto de conhecimento origina-se num impulso sexual infantil, um tipo de voyeurismo e desejo de investigação sexual, a qual é reprimida no decorrer do desenvolvimento. A partir de transformações e sublimações da curiosidade sexual infantil em grande parte reprimida, Freud sustenta que deriva toda a curiosidade subsequente: a luxúria do artista pela beleza, a busca do cientista para penetrar os segredos da natureza, etc. Considerando o evento do Gênesis na história bíblica - retornamos mais longe, para além da infância - podemos refletir o desenvolvimento humano, e encontrar já ali o tabu original sobre o conhecimento do bem e do mal. Foi a curiosidade intelectual de Eva, seu desejo de saber simplesmente, que jogou a ela e Adão numa grande confusão. Para quem tem como tarefa o educar (pais, professores etc.), percebe-se que as crianças são curiosas a respeito de tudo, e não somente a respeito de sexo.

Miller (1987) em seu artigo Curiosidade e suas vicissitudes revela no ensaio do escritor D. H. Lawrence sobre Fantasia inconsciente, ao qual declara que a criatividade é um impulso mais primordial no desenvolvimento humano, o que é também sugerido nos escritos de Otto Rank. Miller (1987) também pensa que a curiosidade reivindica para ela uma força formadora elementar no desenvolvimento humano quanto à criatividade. Ela se encaixa na base fenomenológica por trazer um conceito de intencionalidade no sentido de refletir a experiência subjetiva de um self dirigindo seus significados e objetivos em direção ao mundo.

Cad. de Pesq. Interdisc. em Ci-s. Hum-s., Florianópolis, v.13, n.102, p.202-223 jan/jun 2012 
Através da investigação, a curiosidade procura desmantelar o mundo e conhecê-lo tal como é realmente. A curiosidade em sua total florescência não pressupõe quase nada; ela pode conectar o eu e o outro, a emoção e o intelecto, o impírico e o inato, o impacto da história de vida inicial da pessoa e o imediatismo do contato atual, representando assim um desejo ativo, e é cognitivo sem ser exageradamente abstrato e intelectual. Em outras palavras para Miller (1987) o crescimento psicológico ocorre através da excitação do contato - encontros ativos, criativos, caracterizados pela novidade, curiosidade e incerteza entre o self e o seu mundo.

A curiosidade é ela própria uma força primária que une o bebê em desenvolvimento ao seu ambiente, coloca este indo em direção ao ambiente desde o início, onde tudo é novo e estranho porque está sendo visto pela primeira vez.

Miller (1987) nos lembra da experiência de um pai que ao retornar à casa após o trabalho, encontra seu filho de três anos e lhe interroga: O que há de novo?, a qual o seu filho responde: Tudo!. Talvez essa pudesse ser uma maneira excitante de um adulto viver também, mas iria requerer que permanecêssemos abertos ao desconhecido, ao não familiar, o mistério inerente àquilo que ainda não foi assimilado.

Alice, em sua aventura no País das Maravilhas, quando coisas estranhas começam acontecer, ardia em curiosidade por diversas vezes com tudo que encontrava, e entrava no reino da maravilha e permanecia ali absorvida (LEWIS CARROL, 1865). A maioria dos adultos acha difícil tolerar isso por muito tempo talvez os artistas, empreendedores e cientistas, não.

É comum o desconforto dos adultos diante da curiosidade das crianças e por conta disso as limitações são impostas na família, nas escolas, por mais que se alimente um discurso de abertura e incentivo. A mensagem é geralmente que a curiosidade matou o gato. Em vários dicionários, a curiosidade é descrita também com conotações negativas, tendo sinônimos de inquiribilidade, indiscrição, e que a exploração, investigação quando ultrapassa os limites pode ser castigada e reprimida. Contudo, há também um ditado que diz que a curiosidade é a mãe da ciência. A luta contra Eva e a serpente continua.

Nesse processo de exploração e investigação da busca do conhecimento é normal encontrarmos limites. Já o poeta Drummond se queixava que "no meio do Cad. de Pesq. Interdisc. em Ci-s. Hum-s., Florianópolis, v.13, n.102, p.202-223 jan/jun 2012 
caminho tinha uma pedra". Pois a sociedade se organiza de tal modo a impor ordem, controle e previsibilidade. E a curiosidade, ao contrário, vai para outra direção, do desconhecido e do imprevisível. Achar o caminho do meio, saber equilibrar, dosar a excitação prazerosa da exploração, da descoberta, e da ansiedade que podemos suportar dos seus resultados - a sugestão aqui também serve para os inventores de tecnologias - seria talvez a solução para não tornar a curiosidade patológica, isto é, deixar que a nossa curiosidade participe do mundo, dando forma a ele, conhecendoo, descobrindo-o, e, discriminando nele o que é e o que não é nutritivo para o crescimento pessoal e social. Estar curioso sobre o ambiente, sobre os outros, sobre as circunstâncias de sua própria vida, sobre as responsabilidades éticas, alarga os limites do campo da curiosidade e deixa a pessoa mais madura e seletiva com o real que faz sentido.

Essa postura seria um "bom" caminho para apoiar o argumento racional de Vannevar Bush em seu épico relatório Science, the Endless Frontier, de que - uma razão que remonta ao lluminismo - "a crença de que os progressos [da tecnologia] proporcionados pela pesquisa pura irão mais tarde melhorar a condição humana" (STOKES, 2005, p.157). É claro que Bush emite esse relatório no final da segunda guerra mundial na tentativa de prever o papel da ciência em tempo de paz. E suas premissas eram de que essa pesquisa básica, para não ser tolhida em sua criatividade, deveria ser realizada sem se pensar em fins práticos com característica de contribuir para o conhecimento em geral e ao entendimento da natureza e de suas leis. E que a aplicação desses conhecimentos, dessas descobertas, geraria o progresso tecnológico a fim de satisfazer as necessidades da sociedade, quer econômicas, de defesa, saúde e outras.

Podemos ainda correlacionar o que mencionamos anteriormente sobre pesquisa pura e aplicada, curiosidade e sentido, com o que Stokes propõe em seu livro O quadrante de Pasteur. 
O quadrante de Pausteur

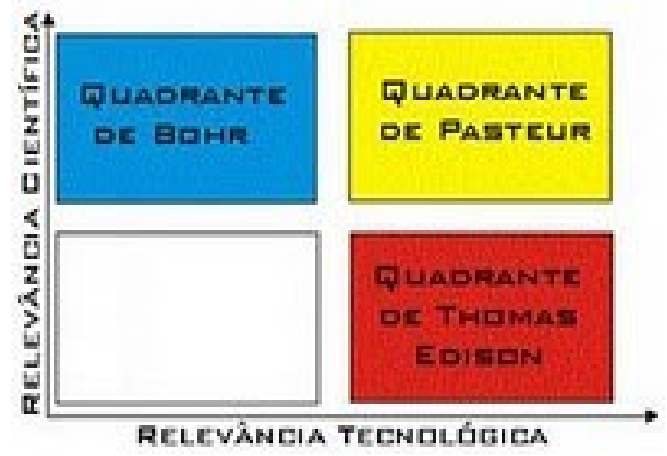

Extraído do site da Radiobrás (www.radiobras.gov.br)

A pesquisa pura dita por Busch pode ser colocada no quadrante de Bohr onde predomina a relevância cientifica, aquela que gera conhecimentos de base, fundamentais, onde não se tem a obrigatoriedade de desenvolvimento de um produto, mas apenas interpretações dos fenômenos da natureza. Já a aplicação desses conhecimentos na sociedade prevista por Busch se desdobraria nos dois quadrantes, se enquadrando primeiramente no quadrante de Thomas Edison, com um pouco de relevância cientifica e pesquisas com perspectivas estratégicas com possibilidade de aplicabilidade. E, num segundo momento, pode-se também fazer parte do quadrante de Pasteur com relevância tecnológica e que incorpora as características dos outros quadrantes descritos e com máxima aplicabilidade dos conhecimentos adquiridos. O quarto quadrante em branco, Stokes omite devido ter morrido prematuramente. Esse quadrante foi posteriormente batizado de "o quadrante de Ruetsap", e pode complementar ou atender todas as necessidades que os outros quadrantes não conseguem suprir. É possível preencher esse espaço em branco com a curiosidade, aquela força formadora elementar no desenvolvimento humano, e encontrar um sentido último para tudo aquilo que o ser humano cria, desenvolve?

\section{Heurística de sentido}

Diante da pergunta do item anterior, nos encontramos diante do poder absoluto ou apenas relativo - que temos da liberdade de escolha de se autodeterminar, da autonomia que temos de inventar nossas necessidades e de Cad. de Pesq. Interdisc. em Ci-s. Hum-s., Florianópolis, v.13, n.102, p.202-223 jan/jun 2012 
criar o programa de nossa vida. A técnica tem o poder de se tornar um recurso, uma estratégia, um meio - e não um fim -, um caminho que aponte na direção da realização de nossos desejos essenciais últimos, de nosso bem-estar. Descobrir seu sentido último pode nos encaminhar para isso.

E alcançamos o sentido quando somos livres. Podemos alcançar a autonomia seguindo o princípio de liberdade exposto por Levy (1990), exercitando nossa faculdade de imaginação, direcionando ela sobre a capacidade de recriação das coisas naturais, segundo as leis objetivas da própria natureza; e da capacidade de criação de uma natureza subjetivamente ordenada, humana para si. "Uma faculdade de desejar, de conceber imaginariamente os fins ou sentidos da vida humana e de viver objetivamente para esses fins ou sentidos" (LEVY, 1990, p. 156). Ser autônomo é saber governar a vida em si mesma pela ordem do desejo, ou pela ordem ética, pois a vida na carência quer material ou de sentido ético, "podem se constituir como fatores degenerativos da condição humana" (1990, p.156).

Isso mostra a natureza dual, multideterminada de nosso ser, onde somos livres até para atentar contra nossa natureza. A vida é feita de instantes de morte, esses instantes nunca voltam e essa transitoriedade da vida nos desfia a fazer o melhor uso possível de cada momento dela.

Frankl (1987), em seu livro Em busca de um sentido, fala sobre a tese do otimismo trágico no sentido da pessoa - criador de tecnologia -, apesar de estar envolto sob os aspectos da tríade trágica, existência humana da dor, culpa e morte, ele pode permanecer otimista. E isto é possível conservando a vida no seu sentido potencial, dizendo sim à vida apesar de tudo. Isso se faz transformando criativamente os aspectos negativos da vida em algo positivo ou construtivo - que pode ser através da técnica -, ou seja, transformando o sofrimento numa conquista e numa realização humana; retirando da culpa a oportunidade de mudar a si mesmo para melhor e fazendo da transitoriedade da vida um incentivo para realizar ações responsáveis. Frankl, também em sua teoria psicológica, utiliza um padrão de comportamento denominado hiperintensão, para dizer que se consegue um comportamento real e efetivo quando há uma razão, um sentido para ser ou fazer algo - uma técnica. Por vezes a pessoa tem - garantido por toda a ilimitação tecnológica contemporânea existente - o suficiente com que viver, porém não tem por que viver. Não é por nada que Ortega y Gasset (1991) nos sugere, no final de

Cad. de Pesq. Interdisc. em Ci-s. Hum-s., Florianópolis, v.13, n.102, p.202-223 jan/jun 2012 
seu livro, que a vida humana não é somente luta contra a matéria, mas também luta do homem com sua alma, e o porquê viver pode ser relacionado com a busca de técnicas da alma. Pode-se encontrar o sentido, eles estão disponíveis apesar do não, através do - sofrimento, da desgraça. O que é então o ser humano? questiona-se Frankl. E responde: "é o ser que sempre decide o que ele é" (1987, p.107). É quem cria a arma; mas é também aquele que pode escolher não puxar o gatilho.

Segundo Frankl (1987), há três caminhos para encontrar um sentido na vida: criar um trabalho ou fazer uma ação - o que está totalmente ligado à técnica -; experimentar algo ou encontrar alguém - amor -; e a capacidade de transformar a tragédia em triunfo, de mudar-se a si mesmo.

Quanto ao primeiro caminho, Frankl nos diz que o sentido emerge e se cristaliza na ação. É a ação que, ao se permitir conduzir pelo sentido, revela o próprio sentido do sentido. Só nos conduzimos em liberdade na ação, nem antes, nem depois, pois somos humanos e por isso agimos, afirmava Hannah Arendt. Por isso teria a técnica, de maneira inicial, a missão de dar liberdade ao homem para que ele possa entregar-se a si mesmo, fazendo suas escolhas subjetivas (ORTEGA Y GASSET, 1991).

Como diz Antônio Machado: Caminante no hay camino, se hace camino al andar (Caminhante, não há caminho, o caminho se faz andando). E caminhando o homem vai fazendo sua própria vida e realizando o seu programa.

E no caminhar de sua criação, o artista, o empreendedor e o cientista podem ir à busca do logos, na sua obra, atividade, pesquisa.

$\mathrm{E}$ com relação à direção, Pinel indica que:

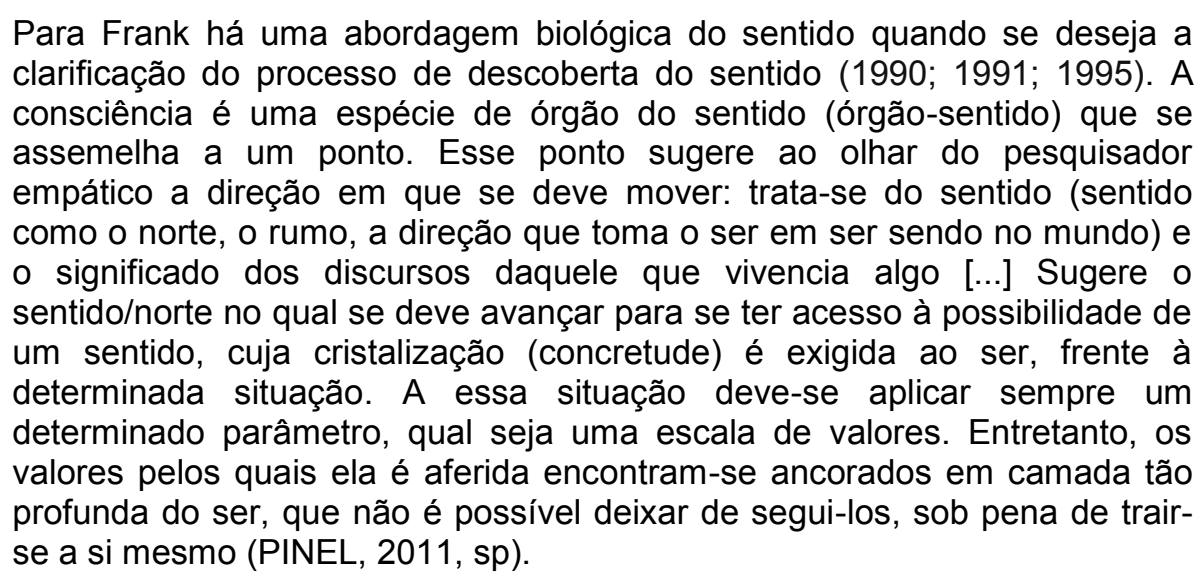

Cad. de Pesq. Interdisc. em Ci-s. Hum-s., Florianópolis, v.13, n.102, p.202-223 jan/jun 2012 
Com certeza podemos afirmar que a técnica não é boa ou ruim por si só. Ortega y Gasset (1991) nos relata que ela chega a diminuir, e por vezes quase elimina o esforço imposto ao homem pela circunstância. E com isso ele se interroga sobre o que o ser humano vai fazer, como ele vai ocupar sua vida se acaso fica sem tarefas impostas pela natureza? Ele então nos diz que a superação da vida animal libera o homem para se dedicar a vários afazeres não biológicos, que não são impostos pela natureza. E por que não - já que o próprio homem inventa tais afazeres - ocupar suas horas da melhor forma possível escolhendo por uma heurística de sentido para aquilo que ele faz? O logos, diz Frankl (1987) é mais profundo que a lógica. Como diz Ortega y Gasset (1991) "o mais trágico do homem é o mais glorioso, pois ele tem obrigação de escolher e, portanto, queira ou não, tem que levar a efeito sua liberdade". Frankl (1987) resume bem o livre-arbítrio do homem cercado pelos limites do meio, quando afirma que o homem, no espaço compreendido por tudo que estimula e a sua resposta, possui a capacidade e liberdade de escolha, sendo responsável por ela.

\section{Por uma ética da responsabilidade}

Há importância em sentir-se responsável por aquilo que fazemos. A vida, diz Frankl (1987) é feita de instantes de morte e esses instantes nunca voltam, e essa transitoriedade da vida nos desfia a fazer o melhor uso possível de cada momento dela. E por isso surge o imperativo: "Viva como se já estivesse vivendo pela segunda vez, e como se na primeira vez você tivesse agido tão errado como estás prestes a agir agora" (FRANKL, 1987, p.126). Esse imperativo pode instigar em nós o senso de responsabilidade - imaginar que o presente é passado e que o passado ainda pode ser alterado e corrigido. Jobs, o cofundador da Apple, em uma de suas últimas declarações, nos deixa uma mensagem que pode ser definida como um hino à vida: "os anos mais bonitos e mais brilhantes estão diante de nós, não às nossas costas" (BRUNI, 2011, p. 41). Jobs, quando pronunciou essa frase, já estava doente, quase morrendo e, ainda assim, olhava para frente.

Um outro imperativo ético também é proposto por Hans Jonas no seu livro 0 Princípio da Responsabilidade. Ele propõe ao pensamento e ao comportamento 
humano uma nova ética, pois a ética tradicional funda-se apenas dentro dos limites do ser humano e despreza a natureza. Ele propõe, portanto, um novo imperativo ético: "Age de tal maneira que os efeitos de tua ação sejam compatíveis com a permanência de uma vida humana autêntica", ou formulando negativamente, "não ponhas em perigo a continuidade indefinida da humanidade na Terra" (JONAS, 2006, p. 18). Essa ética não se apresenta como uma realidade visível, mas se presencia como um chamado sensato que pede paciência, prudência e equilíbrio. A esse chamado Jonas nomeia de Princípio de Responsabilidade.

Já na apresentação do livro, Maria Clara Lucchetti comenta que "para que haja responsabilidade é preciso existir um sujeito consciente. Contudo, o imperativo tecnológico elimina a consciência, elimina o sujeito, elimina a liberdade em proveito de um determinismo" (JONAS, 2006 p.18). Na mesma direção, Fernandes (2008, p. 5 , grifo nosso) indica

que quanto mais a racionalidade se desloca da consciência subjetiva e se instala em automatismos e suportes materiais (como o dinheiro e o próprio processo produtivo e a tecnologia,), tanto mais o indivíduo corre o risco de se esvaziar de suas prerrogativas, mediante a formalização das relações.

Para Jonas (2006) o Homo faber está acima do Homo sapiens, o que faz que a tecnologia assuma um significado ético, ocupando um lugar central na subjetividade, relativo aos fins da vida humana, como um fim e não como um meio cobrado pela necessidade. E ainda que "o homem atual é cada vez mais produtor daquilo que ele produziu e o feitor daquilo que ele pode fazer" (JONAS, 2006, p.44), ocasionado, principalmente, segundo afirma Illich (1976, p.23), que "o domínio do homem sobre a ferramenta foi substituído pelo domínio da ferramenta sobre o homem".

Se a esfera do produzir invadiu o espaço do agir essencial provocando a violação da natureza, Jonas propõe então que a moralidade (o sentido) deve invadir a esfera do produzir, da qual ela se mantinha afastada anteriormente. Ainda que as formas tradicionais de ação moral e ética devam continuar existindo, a responsabilidade diante de um futuro indefinido precisa de ações mais efetivas. Diante dos novos fenômenos tecnológicos, a política e a ação coletiva passam para o centro da ética da responsabilidade, pois não se "pode evitar que o meu agir afete o destino de outros, portanto arriscar aquilo que é meu significa sempre arriscar Cad. de Pesq. Interdisc. em Ci-s. Hum-s., Florianópolis, v.13, n.102, p.202-223 jan/jun 2012 
também algo que pertence a outro, e sobre o qual, a rigor, não tenho nenhum direito" (JONAS, 2006 p.84); onde "o novo imperativo está endereçado muito mais à política pública que à conduta privada" (JONAS, 2006, p. 48).

Corrobora com esse pensamento Laufer, em seu artigo sobre a dimensão ética na ciência e tecnologia, quando nos diz que

\begin{abstract}
todos aqueles que estão envolvidos na formulação e execução das políticas de ciência e tecnologia tem sua quota de responsabilidade, quem tem maiores e mais imediatos conhecimentos sobre os benefícios e perigos de um aspecto determinado de uma aplicação dos avanços científicos e tecnológicos tem uma responsabilidade especial adicional de usar essa percepção. A responsabilidade ética do investigador é primária. Esta responsabilidade não é grande ou pequena (...) é permanente, pois o conhecimento implica corresponsabilidade moral. (...) Mas hoje em dia os aspectos éticos da ciência e a tecnologia abrangem todos os campos do saber científico e também suas relações com a sociedade e sua responsabilidade frente a ela (LAUFER, 2006, p.1).
\end{abstract}

Para Jonas, devido ao abuso do homem no domínio sobre a natureza através da técnica -, causando sua destruição, Ihe faculta uma relação de responsabilidade com a natureza, haja vista que ela está sobre o seu poder. Eisler (2003) fala d'O poder letal da espada - o poder de tirar, em vez de dar a vida, o poder definitivo para estabelecer e impor a dominação.

Ainda Eisler (2003) enfatiza que hoje nos encontramos em outro ponto de bifurcação potencialmente decisivo: numa época em que "o poder letal da espada" — amplificado um milhão de vezes pelos megatons das ogivas nucleares - ameaça pôr um fim a toda cultura humana, às novas descobertas sobre as histórias modernas e antigas.

Portanto, para Jonas, estando o homem em relação com a natureza, se faz necessário superar a ética antropocêntrica e se filiar a uma ética que contemple também a natureza. Por isso a responsabilidade na ética deve ser vista na articulação de duas realidades: uma subjetiva - a do sujeito - e uma objetiva - da ação do sujeito. Para essa responsabilidade existe um "arquétipo de todo agir responsável que a natureza implantou solidamente em nós (ou pelo menos na parte da humanidade que procria)", que é o dever para com a posteridade relacionada à responsabilidade de precaução e assistência para com os filhos (JONAS, 2006 p. 90). Para isso é importante não perdermos a noção de continuidade da vida, pois na natureza não há fim sem começo, tudo é continuidade.

Cad. de Pesq. Interdisc. em Ci-s. Hum-s., Florianópolis, v.13, n.102, p.202-223 jan/jun 2012 
Posto isso, poderemos então repensar o modelo de desenvolvimento tecnológico atual e optar por um estilo de desenvolvimento que possa contemplar como estratégia a sustentabilidade, ou seja, um desenvolvimento sustentável, preocupado com a qualidade de vida e o bem-estar das pessoas; desenvolvimento este definido pelo Relatório de Brundtland, documento publicado em 1987, intitulado "Nosso Futuro Comum" (Our Commom Future), trouxe o inédito conceito de Desenvolvimento Sustentável como o desenvolvimento que satisfaz as necessidades básicas e as aspirações de bem estar da população do presente, sem comprometer a capacidade das gerações futuras. Aqui, neste conceito de desenvolvimento sustentável, já se observa um certo senso de responsabilidade. Este relatório, segundo Brüseke (2009, p. 33), "parte de uma visão complexa das causas dos problemas sócio-econômico-ambiental da sociedade global" e que "sublinha a interligação entre economia, tecnologia, sociedade e política", chamando também "a atenção para uma nova postura ética, caracterizada pela responsabilidade tanto entre as gerações, quanto entre os membros contemporâneos da sociedade atual".

Diante da responsabilidade de pensar nas gerações futuras, pode-se falar numa ética imperativa de que deve haver, independentemente, um futuro (de tal ou tal feitio) com situações futuras extrapoláveis do homem e do mundo que devem ser submetidas ao julgamento da ética, dos princípios.

\section{6 À procura de uma conclusão}

Cada época tem sua neurose coletiva ou Weltanschauung - talvez a nossa seja a da tecnologia - e cada época necessita de sua própria "psicoterapia" para enfrentá-la. Para tanto, uma heurística de sentido é a proposta para mudar essa capacidade humana de perceber a realidade sensível. Pois a tecnologia tem nos empurrado em geral para um mundo intangível, para uma vida imagética.

A tecnologia, com maiores ou menores impactos, tem conformado nossas vidas. Estamos à mercê de sistemas interconectados, transistores, bytes, hardware, software, o que é grave, pois estamos nos sentindo subservientes à sua autoridade, moldando-nos ao seu funcionamento. Grande parte de nós nem faz ideia do que realmente deseja. Desejamos alguma coisa, mas não sabemos o que é. Isso nos 
converte, gostemos ou não, em participantes de uma nova ordem na história, acantonando-nos num sistema tal que nos coloca face a face com uma cultura que podemos chamar de 'tecnopolista', engendrada numa era tecnológica (PINTO, 2005), sujeitando-nos ao que Winner, pertinentemente, chamou de sonambulismo tecnológico (BAZZO, 1998).

Acostumamo-nos a essa era tecnológica e sabemos que há na sociedade interesses que validam essa Weltanschauung ao qual somos protagonistas quando nos tornamos os financiadores, inventores e produtores de tecnologias, e vítimas ao mesmo tempo quando somos consumidores passivos que autorizam a entrada dentro de nossas vidas dessa cultura tecnopolista, que acabam alterando toda uma gama de valores estéticos, morais, cognitivos etc., influenciando nosso modo de agir.

N'O Capital, Marx (2008) nos diz que a tecnologia revela o modo de agir do homem com respeito à Natureza, o processo de produção, por meio do qual ele mantém sua vida - satisfaz suas necessidades - e, dessa forma, também desnuda o mecanismo de formação de suas relações sociais e das concepções intelectuais delas decorrentes. O foco da discussão de Marx sobre a mudança tecnológica não está, portanto, nos indivíduos, não importa quão heroicos sejam eles, mas num processo social, coletivo, no qual os ambientes institucional e econômico desempenham papéis fundamentais. Corrobora com isso Jonas (2006) quando localiza e direciona o imperativo ético mais à política pública que à conduta privada.

Todavia, em uma extensão mais ampla podemos também afirmar que as Weltanschauung, essas percepções de mundo, nem sempre são compartilhadas por todos de uma sociedade, e às vezes se restringem a grupos sociais de interesses específicos e minoritários. Esses interesses de grupos sociais majoritários se juntam e formam aquilo que Peter Berger ousa chamar de estrutura de plausibilidade, estrutura essa que legitima e regula o discurso desses grupos que acaba sendo aceito e compartilhado dentro de uma determinada Weltanschauung. Porém essa Weltanschauung é dinâmica e pode ser alterada, pois conforme Berger e Luckmann (1985, p. 75) "os homens em conjunto produzem um ambiente humano, com a totalidade de suas formações sócio-culturais e psicológicas", isto é, podemos também ter uma Weltanschauung individual que dê sentido à tecnologia e que pode ser compartilhada com outras pessoas. Experiências éticas que possam ser trocadas com outros indivíduos e grupos, e que resultem, que contribuam para

Cad. de Pesq. Interdisc. em Ci-s. Hum-s., Florianópolis, v.13, n.102, p.202-223 jan/jun 2012 
formação de uma Weltanschauung global que amplie o modo de perceber o processo de criação, produção e consumo de tecnologia. O modo como recebo e processo interiormente essas percepções da era tecnológica, e de maneira ativa construo minha Weltanschauung privada, individual e depois social, irá servir de contribuição para a construção de uma visão de mundo, de uma Weltanschauung global.

Observamos que a curiosidade nos impulsiona para a busca sem limites do conhecimento e causa preocupações com o cometimento de abusos e exageros nascidos daí, o que acaba dividindo a conduta e o posicionamento do homem a respeito dessas ações, quer individual, quer coletiva. Surge então a teoria ética como a necessidade de justificar racionalmente as condutas dessas ações, diante da própria consciência e diante dos demais. Ética é um feito e um discurso; existe porque uma dada conduta pode ser avaliada por meio de descrições que a apresentam como boa ou má. A questão volta: como saber se uma ação é boa ou má?

Costa (1994) parte do princípio, aparentemente óbvio, de que só podemos julgar moralmente uma conduta quando podemos reconhecê-la como portadora de um sentido ético. Para Laufer (2006) os dilemas éticos da ciência não se resolvem estabelecendo comitês, normas e códigos, senão através da cabal compreensão, por parte de todos os atores, das implicações e efeitos das descobertas científicas. Cabe recordar que quanto mais sabemos, mais ignoramos da realidade, e também das consequências de nosso saber.

Afirmamos que os fatores fundamentais para o desenvolvimento tecnológico e todas as questões decorrentes dele tem como ponto causal o homem, isto é, conforme argumenta Gusdorf (1977), todas as atividades científicas deveriam, em última estância, visar o homem.

Antes de existir o trabalho, o capital, a técnica, existe o homem e sua inteligência. É o homem que com sua criatividade entra em relação com os outros homens e as coisas, e assim confere valor e sentido. E como ser social, o ser humano sempre está reagindo à sua cultura social e pessoal. 
Por fim, como diz Zinker (2007, p. 91)

somente o artista [o cientista, o empreendedor], pode se conhecer em profundidade e avaliar a sua honestidade. Ele sabe quando está representando [inventando, empreendendo]. Sabe quando apenas quer fazer que os outros chorem, riam ou se impressionem. No instante que perde o contato com sua honestidade [sentido último], perde também seu eixo impecável e inegociável.

O ser humano perde, conforme Vieira Pinto (2005), o seu "maravilhar-se". 


\section{REFERÊNCIAS}

ARRUDA, Bertoldo Kruse Grande de. Ciência, tecnologia e sociedade. Rev. Bras. Saude Mater. Infant. [online]. 2006, vol.6, n.2, pp. 159-160. ISSN 1519-3829.

BAZZO, Walter. Ciência, Tecnologia e Sociedade e o contexto da educação tecnológica. Florianópolis: editora UFSC, 1998. Disponível em:

<http://www.campus-oei.org >. Acesso em 02/12/2011.

BERGER e LUCKMANN, Construção social da realidade: tratado de sociologia do conhecimento. Petrópolis: Vozes, 1985.

BRUNI, L. O legado de Steve Jobs. Cidade Nova, São Paulo, ano LIII, n. 11, p. 41, Nov. 2011.

BRÜSEKE, J. F. O problema do Desenvolvimento Sustentável. In: CAVALCANTI, Clovis (Org.) Desenvolvimento e natureza: estudos para uma sociedade sustentável - 5. Ed. - São Paulo: Cortez; Recife, PE: fundação Joaquim Nabuco, 2009.

CMMA. Our Commom Future. Disponível em: < http://www.onu.org.br/a-onu-emacao/a-onu-e-o-meio-ambiente/>. Acesso em: 31/01/2012.

COSTA, Jurandir Freire. Ética e o espelho da cultura. Rio de Janeiro: Rocco, 1994.

EISLER, Riane. O Cálice e a Espada - nossa história, nosso futuro. Rio de Janeiro: Palas Atenas, 2003.

FRANKL, Viktor E. Em busca de Sentido: Um psicólogo no campo de concentração. Porto alegre: Sulina, 1987.

FERNANDES, Valdir. A racionalização da vida como processo histórico: crítica à racionalidade econômica e ao industrialismo. Cadernos EBAPE. BR, v. 6, n. 3, Set. 2008.

FADIMAN, J, FRAGER, R. Teorias da personalidade. Tradução Odette de Godoy Pinheiro. São Paulo: Habra, 1986. 
FREUD, Sigmund [1916]. Instinto e suas Vicissitudes. Edição Standard Brasileira das Obras Psicológicas Completas. Vol. XIV. Rio de Janeiro: Imago, 1996.

FREUD, Sigmund [1910]. Leonardo da Vinci e uma Lembrança de sua Infância, idem, vol. XI.

FURTADO, C. Cultura e Desenvolvimento em época de crise. Rio de Janeiro: Paz e Terra, 1984.

GUSDORF, G. A interdisciplinaridade. Ciências Humanas. Rio de Janeiro, 1(2):13-22, jul.set., 1977.

ILLICH, Ivan. A convivencialidade. Lisboa: Europa-América, 1976.

JONAS, Hans. O Princípio da Responsabilidade: ensaio de uma ética para uma civilização tecnológica - Rio de Janeiro: Contraponto:/Ed PUC -Rio, 2006.

KANT, Immanuel. Crítica da faculdade do juízo. Tradução de Valério Rohden e António Marques. Rio de Janeiro, RJ: Forense Universitária, 1993.

LAUFER, Miguel. A dimensão ética na ciência e a tecnologia. INCI. [online]. jul. 2006, vol.31, no.7 [citado 21 Enero 2012], p.475-475. Disponível em:

<http://www.scielo.org.ve/scielo.php?script=sci_arttext\&pid=S0378-

18442006000700003\&Ing=es\&nrm=iso>. ISSN 0378-1844. Acesso em 03/12/2011.

LEVY, Nelson. O Desejo/organizador. São Paulo: Companhia das Letras/ FunarteRJ, 1990.

LEWIN, Kurt. Princípios de Psicologia Topológica. São Paulo: Cultrix, 1973.

LEWIN, Kurt. Teoria de Campo em ciência social. Trad. de Carolina Martuscelli Bori. São Paulo: Pioneira Ed.,1965.

MARX, Karl [1867]. O capital. Rio de Janeiro: Civilização, 2008. 
MILLER, M. V. Curiosidade e suas vicissitudes. The Gestalt Journal. vol. X, n. 1, Spring, 1987. Traduzido por Alina Purvinis.

ORTEGA Y GASSET, José [1939]. Meditação sobre a técnica. [tradução de José Francisco Pinto de Almeida Oliveira]. Rio de Janeiro: Instituto Liberal, 1991.

PERLS, Frederick S. Ego, fome e agressão: uma revisão da teoria e do método de Freud. [Tradução Georges D. J. Bloc Boris]. - São Paulo: Summus, 2002.

PINTO, Álvaro Vieira. O conceito de tecnologia. vol. I. Rio de Janeiro: Contraponto, 2005.

PINEL, Hiran. O Conceito de "Otimismo Trágico" de Viktor Emil Frankl:

Subsídios para o Exercício do/no Ofício Educador Social. 2011. Disponível em: $<$ http://artigos.psicologado.com/atuacao/psicologia-social/o-conceito-de-otimismotragico-de-viktor-emil-frankl-subsidios-para-o-exercicio-do-no-oficio-educadorsocial\#ixzz1k2GlqqTP>. Acesso em 04/12/2011.

RAYNAUT, Claude. Interdisciplinaridade: mundo contemporâneo, complexidade e desafios à produção e à aplicação de conhecimento. In: PHILIPPI JR., A. \& SILVA NETO, A. J. Interdisciplinaridade em ciência, tecnologia \& inovação. Barueri: Manole, 2011.

STOKES, Donald E. O quadrante de Pasteur: a ciência básica e a inovação tecnológica. Campinas: EdUNICAMP, 2005.

TELLEGEN, T. A. Gestalt e grupos: uma perspectiva sistêmica. São Paulo: Summus, 1984.

WIKIPEDIA ONLINE, <http://pt.wikipedia.org/wiki/Weltanschauung>. Acesso em 01/12/2011.

ZINKER, Joseph. Processo criativo em Gestalt-terapia. [Tradução de Maria Silvia Mourão Netto]. São Paulo: Summus, 2007.

Artigo:

Recebido em: 15/02/2012

Aceito em: $31 / 07 / 2012$ 